University of Wollongong

Research Online

Faculty of Engineering and Information

Faculty of Engineering and Information

Sciences - Papers: Part B

Sciences

2019

\title{
Vibration control of a tunnel boring machine using adaptive magnetorheological damper
}

\author{
Bo Yang \\ Northeastern University, University of Wollongong \\ Shuaishuai Sun \\ University of Wollongong, ssun@uow.edu.au \\ Lei Deng \\ University of Wollongong, Id530@uowmail.edu.au \\ Tianhe Jin \\ Beijing Jiaotong University \\ Weihua Li \\ University of Wollongong, weihuali@uow.edu.au
}

See next page for additional authors

Follow this and additional works at: https://ro.uow.edu.au/eispapers1

Part of the Engineering Commons, and the Science and Technology Studies Commons

Research Online is the open access institutional repository for the University of Wollongong. For further information contact the UOW Library: research-pubs@uow.edu.au 


\title{
Vibration control of a tunnel boring machine using adaptive magnetorheological damper
}

\author{
Abstract \\ With a large number of tunnel boring machines (TBM) being used in various tunnel constructions, the \\ vibration problem under complex geological conditions have become increasingly prominent. In order to \\ solve the problem, this article investigates the application of an adaptive magnetorheological (MR) \\ damper on the vibration reduction of a TBM. The MR damper could reduce the horizontal vibration of the \\ TBM system and adjust its dragging force on the propulsive system under different geological conditions. \\ The MR damper can also provide large enough damping force even under a small amplitude vibration, \\ which is required by TBM. In this paper, an MR damper was designed, prototyped and its properties were \\ tested by an MTS system, including its current-dependency, amplitude-dependency and frequency- \\ dependency features. A scaled TBM system incorporated with the MR damper was built to evaluate the \\ vibration reduction effectiveness of the MR damper on the TBM system. The experimental test results \\ demonstrate that the displacement and the acceleration amplitudes of the TMB vibration could be \\ reduced by $52.14 \%$ and $53.31 \%$, respectively.

\section{Disciplines} \\ Engineering | Science and Technology Studies

\section{Publication Details} \\ Yang, B., Sun, S., Deng, L., Jin, T., Li, W. \& Li, H. (2019). Vibration control of a tunnel boring machine using \\ adaptive magnetorheological damper. Smart Materials and Structures, 28 (11), 1-15.
}

\section{Authors}

Bo Yang, Shuaishuai Sun, Lei Deng, Tianhe Jin, Weihua Li, and He Li 


\title{
Vibration control of a tunnel boring machine using adaptive magnetorheological damper
}

\author{
Bo Yang ${ }^{1,2}$, ShuaiShuai $\mathrm{Sun}^{2}$, Lei Deng ${ }^{2}$, Tianhe $\mathrm{Jin}^{3}$, Weihua $\mathrm{Li}^{2}, \mathrm{He} \mathrm{Li}^{1}$ \\ 1. School of Mechanical Engineering and Automation, Northeastern University, Shenyang \\ 110819, China; \\ 2. School of Mechanical, Materials, Mechatronic and Biomedical Engineering, University of \\ Wollongong, New South Wales 2522, Australia; \\ 3. School of Mechanical, Electronic and Control Engineering, Beijing Jiaotong University, \\ Beijing 100044, China \\ E-mail: $\underline{\text { hli@mail.neu.edu.cn } \text { and ssun@uow.edu.au }}$
}

\begin{abstract}
With a large number of tunnel boring machines (TBM) being used in various tunnel constructions, the vibration problems under complex geological conditions have become increasingly prominent. In order to solve this problem, this article investigates the application of an adaptive magnetorheological (MR) damper on the vibration reduction of a TBM. The MR damper could reduce the horizontal vibration of the TBM system and adjust its dragging force on the propulsive system according to different geological conditions. The MR damper can also provide large enough damping force even under a small amplitude vibration, which is required by TBM. In this paper, an MR damper was designed, prototyped and its properties were tested by an MTS system, including its current-dependency, amplitude-dependency and frequency-dependency features. A scaled TBM system was built to evaluate the effectiveness of the MR damper on the vibration reduction of TBM system. The experimental evaluation results demonstrate that the displacement and the acceleration amplitudes of the TMB vibration could be reduced by $52.14 \%$ and $53.31 \%$, respectively.
\end{abstract}

Keywords: magnetorheological (MR) damper, tunnel boring machine (TBM), semi-active vibration reduction.

\section{Introduction}

Tunnel boring machine (TBM) has been used more and more for a wide range of tunnel excavations, such as subway tunnel, road tunnel, drinking water tunnel, and municipal pipe network tunnel. During these tunnel constructions, complex geological environments often hinder the smooth excavation [1,2]. Boring blocky rock mass and hard rock causes violent vibration, which is easy to loosen the pipeline, damage the mechanical system, and even lead to off-course of the TBM in the horizontal direction [3,4]. Practical examples of mechanical damage associated with severe vibrations can be found in many papers. For instance, Bilgin [5] et al. records that there are $20 \%$ mechanical failures related to vibration, including hydraulic hose failure and steering cylinder failure during the Tarabya tunnelling. Zou et al. [6] present that severe vibration led to some problems on TBM such as reduced penetration rate and damaged disc cutter in Dahuofang railway tunnel, Qinling water tunnel and Liaoxibei Water tunnel. Huo et al. [7] measured a Robbins TBM in Liaoning northwest project. The result shows that the measured horizontal acceleration of a cutterhead reached $1.5 \mathrm{~g}$ to $2.5 \mathrm{~g}$ in normal excavation conditions.

The above research has shown that the TBM is accompanied by severe vibrations during hard rock excavation. It is essential to reduce these vibrations using different methods and devices because severe vibration increases the maintenance cost and reduces the efficiency of tunneling. 
The existing vibration reduction measures are only for some accessories on TBM. For instance, Xie et al. [8] analyses the fluid structure interaction of a hydraulic piping system of TBM. It is significant to suppress pipe vibrations by optimizing pipeline length. The author of this article developed a MR damper and T-S fuzzy controller for segment erector vibration reduction, which is installed on a TBM. Compared to a passive damper, MR damper reduces vibration acceleration by $32.1 \%$ under a random excitation [9]. In addition, wire saw cutting technique was proposed in underground tunnel excavation as a vibration reduction method by Gustafsson [10]. Lee et al. [11] improved this technique by mounting a wire saw around center blast area and a significant vibration reduction is observed. However, the above methods only investigated the vibration reduction of TBM components or need to make major changes to TBM.

In addition to the above methods, increasing the damping of the TBM structure is another effective method. However, the conventional passive damper cannot satisfy the requirements of the TBM because of the following two reasons. Firstly different damping is required under different excavation conditions. Specifically, during the hard rock excavation, the vibration of the girder is fierce and requires large damping force to attenuate the vibration; however, during soft rock excavation, the large damping is not required because only slight vibration exists and large damping force, conversely, will significantly increase the requirement of propulsion force. On the other hand, the vibration amplitude of the TBM is small, thus it is hard to design a conventional damper to generate large enough damping force under small amplitude vibration. In order to resolve these issues, adaptive MR damper is proposed to control the vibration of TBM in this paper. MR fluid is one kind of smart fluid, whose yield stress can be adjusted in millisecond level $[12,13]$. MR damper is a controllable damper filled with MR fluids and its damping can be rapidly controlled. Because of the high adaptability of the MR damper, it has been widely applied in many fields, including vehicle suspension, impact protection, vibration control, adaptive robotic technology, etc. [14-22]. The controllability of the MR damper can satisfy the requirements of different geological conditions. In addition, the high yield stress of MR fluids under magnetic field enable the MR damper to have the capability of generating large damping force under low vibration amplitude, which is an ideal feature required by the vibration attenuation of TBM. In this paper, an MR damper is designed, prototyped and characterized for a scaled TBM in Section 2. Section 3 introduced the testing system, conducted the evaluation of the scaled TBM installed with MR damper and analyzed the testing results. The conclusion is drawn in Section 4.

\section{Construction of a scaled TBM installed with an MR damper}

During the process of breaking the rock by TBM, the unbalanced moment and impact load can cause severe vibration. As a result, the equipment, piping line and electrical devices on the TBM often damage. In order to solve this problem, it is necessary to employ the MR damper because it can generate enough damping fore.

\subsection{The design of a scaled TBM}

In order to evaluate the effect of the MR damper on TBM vibration reduction, an 1:35 scaled TBM testing platform, as shown in Figure 1, is designed and manufactured following a real TBM (type $880 \mathrm{E}$, Aker Wirth corp.). The specific parameter comparison of the scaled TBM and the real TBM is provided in Table1. 


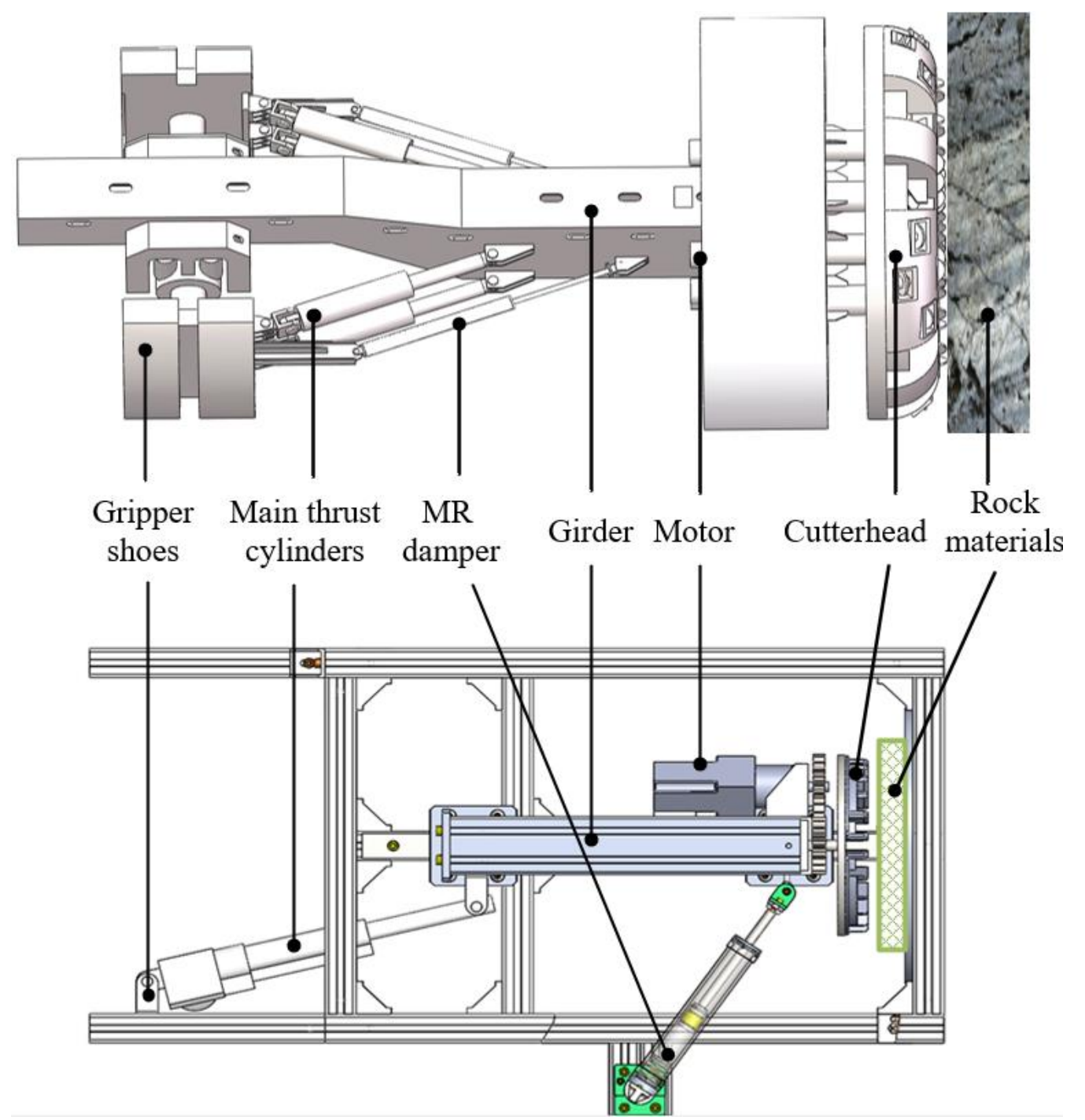

Figure 1. Structure of TBM installed with an MR damper

Table 1. Comparison between real TBM (model: 880E) and the scaled TBM

\begin{tabular}{ccc}
\hline Items & TBM $880 \mathrm{E}$ & Test platform \\
\hline Dimensions & $25530 \times 8800 \times 8800 \mathrm{~mm}$ & $728 \times 250 \times 250 \mathrm{~mm}$ \\
tunneling speed & $3.5 \mathrm{~m} / \mathrm{h}$ & $1 \sim 5 \mathrm{~m} / \mathrm{h}$ \\
Rotating speed of cutterhead & $5.4 \mathrm{rpm}$ & $5 \mathrm{rpm} \sim 50 \mathrm{rpm}$ \\
Motor power of the cutterhead & $8 \times 430 \mathrm{KW}$ & $1 \times 0.75 \mathrm{KW}$ \\
Main drive mode & gears & gears \\
\hline
\end{tabular}

The test platform consists of three parts: propulsion module, rotary cutting module, and damper module. Propulsion module is made up of a linear actuator and a linear guideway, which can simulate the motion characteristics of the gripper and main thrust cylinders of TBM. The rotary cutting module comprises of a servo motor, a planetary reducer, a pair of spur gears and a plate, which is used to imitate TBM's cutterhead and its driving system. On the plate of the test platform, metal and plastic cutters are installed to imitate a real cutter to cut materials of various hardness and density, driven by the servo motor. 3D printed plastic materials and foams are installed on a plate in front of the cutterhead, as shown in Figure.1, to simulate the hard rock materials and soft rock materials during the testing, respectively. Regarding the damper module, one end of the damper is connected to the gripper shoes, and the other end is connected to the girder. When the main thrust cylinders move forward, the MR damper's rod also moves. Following the practical installation, the scaled MR damper module is mounted between the 
girder of the scaled TMD and the frames via two joints.

\subsection{Structure of the MR damper}

The structure of the MR damper is shown in Figure 2(a). In this design, a slider is mounted between the steel cylinder and the piston to reduce the unbalance of the damper rod. For another thing, a plunger subassembly which consists of O-rings, a plunger, bolts, and nuts, makes the sealing better during spring compression. Dimensions of the main components are shown in Figure 2(b). The pushrod can move $120 \mathrm{~mm}$ from right limited position to front seal cap. The manufactured MR damper is shown in Figure 2(c). MRF (MRF-132EG, Lord corp.) is filled in the chamber of steel cylinder, and the gap between steel cylinder and damper coil is $1 \mathrm{~mm}$. The compressed spring and pole piece are made of AISI1065 steel and AISI 1012 steel, respectively.

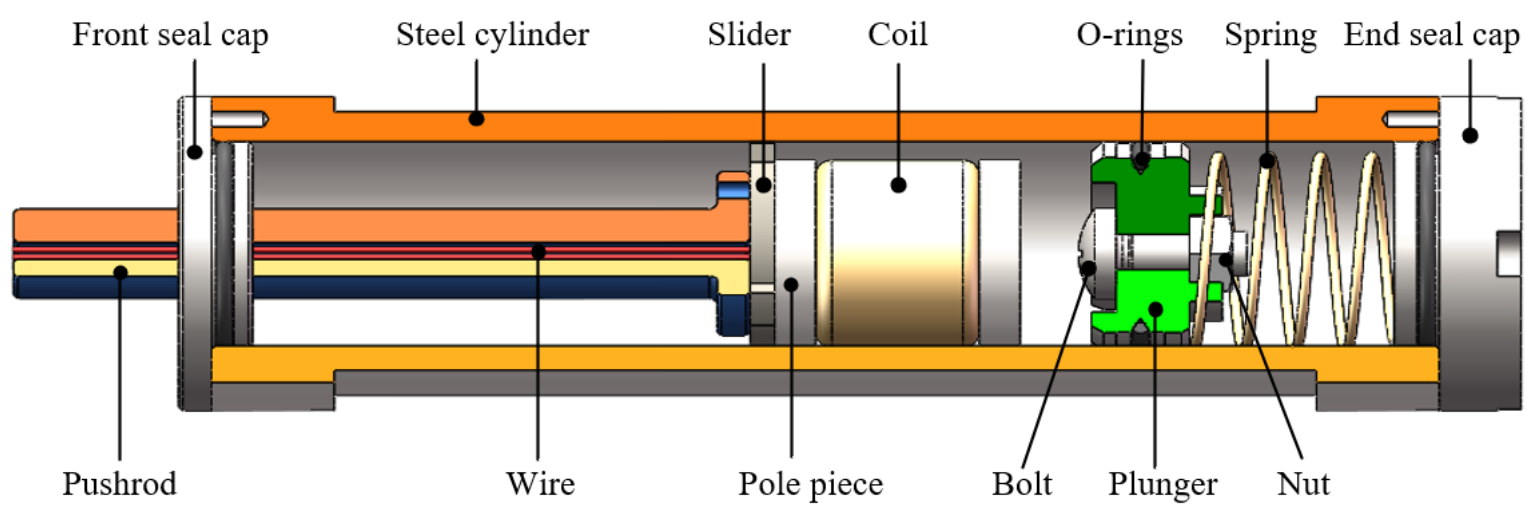

(a)

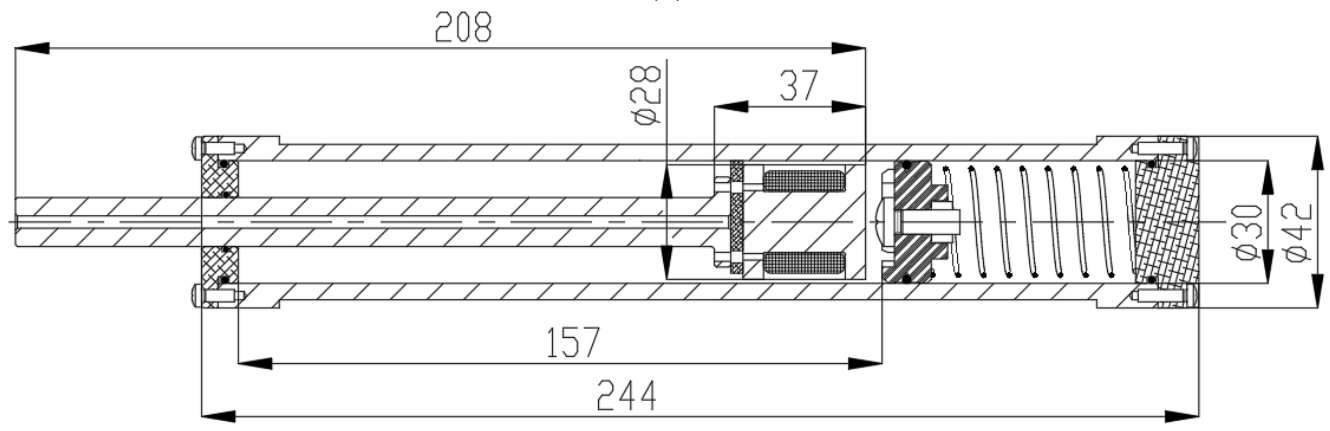

(b)

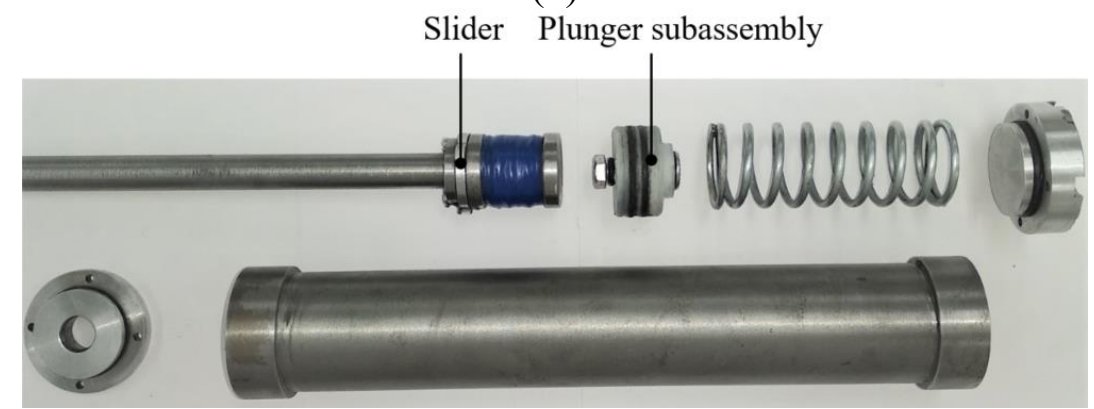

(c)

Figure 2. The structure of MR damper

(a) Design drawing (b)Dimensions of the main components (c) Manufactured damper components

\subsection{Magnetic field simulation of the MR damper}


In order to provide guidance to the damper design, the induced magnetic field of the MR damper was simulated by COMSOL software with a two-dimensional (2D) axisymmetric study and shown in Figure 3(a). The magnetic flux of the MR increases continuously with the increasing current. The maximum mean flux of the damper was found to be $0.51 \mathrm{~T}$ at $2.5 \mathrm{~A}$. The damper shows saturation when the current was set at $2.5 \mathrm{~A}$. As a result, the current range of 0-2.5 A was chosen to be used in the tests. Parameters of the electromagnetic coil are shown in the Table 2.

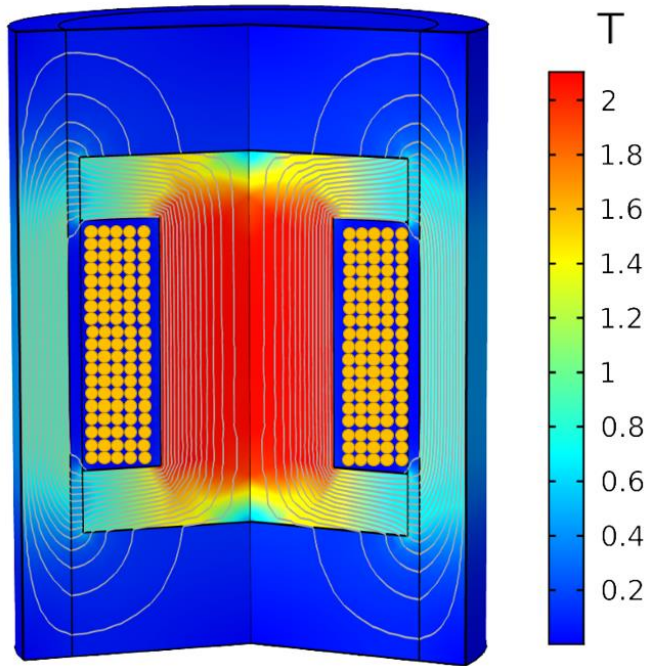

(a)

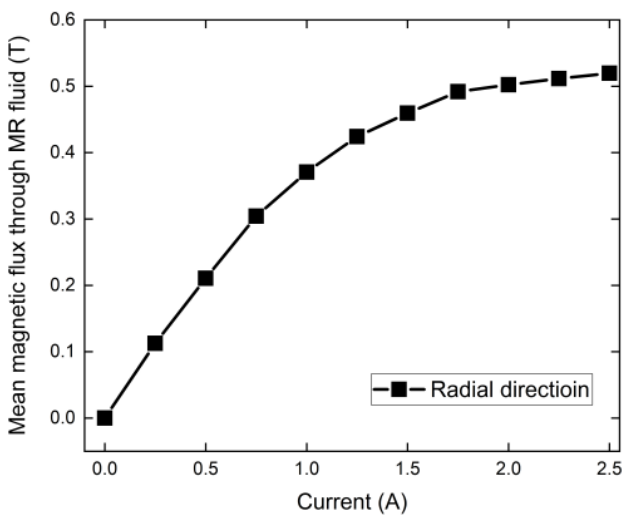

(b)

Figure 3. Magnetic field simulation (a) modelled damper and (b) average flux through the MRF for varied currents

\begin{tabular}{cc}
\hline \multicolumn{2}{c}{ Table 2. Parameters of the electromagnetic coil } \\
\hline Items & Parameter \\
Turns & 200 \\
Diameter & $0.5 \mathrm{~mm}$ \\
Electrical conductivity & $5.998 \mathrm{e} 7 \mathrm{~S} / \mathrm{m}$ \\
Resistance & $10.9 \Omega$ \\
\hline
\end{tabular}

\subsection{Testing of the MR damper}

In order to verify the variable damping feature of the designed MR damper, MTS testing was conducted under a wide range of testing conditions. The testing system is shown in Figure 4. The test input is selected as the sinusoidal signal $x=A \cdot \sin (2 \pi f t)$ to characterize the damping of the device. $x, A, f$ and $t$ represent the displacement, amplitude, frequency and time, respectively. The amplitude and frequency of the excitation can set via control software. 


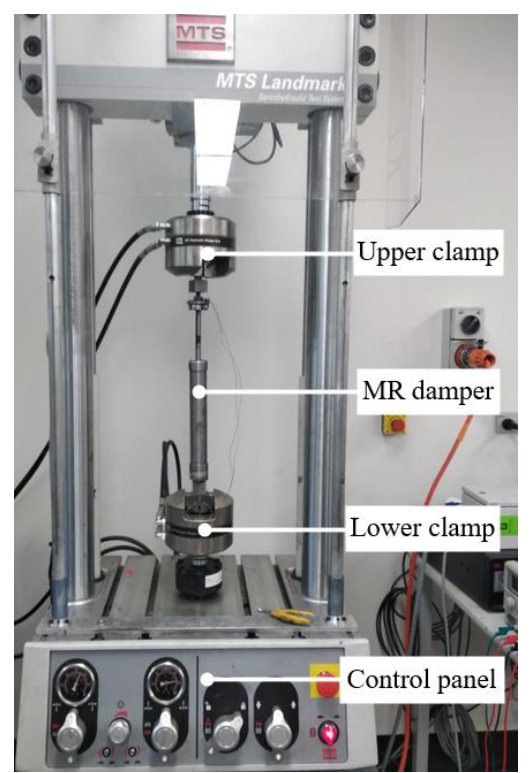

Figure 4. MTS testing of MR damper

\subsubsection{Current dependency}

In order to investigate the relationship between the damping force and the input current, the MTS machine was programmed to generate $10 \mathrm{~mm}$ amplitude excitation with a frequency of $1 \mathrm{~Hz}$. Figure 5 shows the damping variability in response to various currents: $I=0,0.5,1,1.5$, $2,2.5 \mathrm{~A}$. The equivalent damping coefficient is calculated using the following equation $[23,24]$.

$$
c_{e q}=\frac{\mathrm{EDC}}{2 \pi^{2} f \Delta^{2}}
$$

Where EDC is the energy dissipated per cycle, $f$ is the loading frequency and $\Delta$ is the maximum displacement from the equilibrium position.

As shown in Figure 4(a), the enclosed area of force-displacement loops, EDC, increases with the damper current increase from 0 to $2.5 \mathrm{~A}$. The calculated equivalent damping coefficient is given in Figure 4(b). The calculation results show that the damping increases $233 \%$ from 1592.35 to 5302.55 N.s.m ${ }^{-1}$ with the increase of current from 0 to $2.5 \mathrm{~A}$.

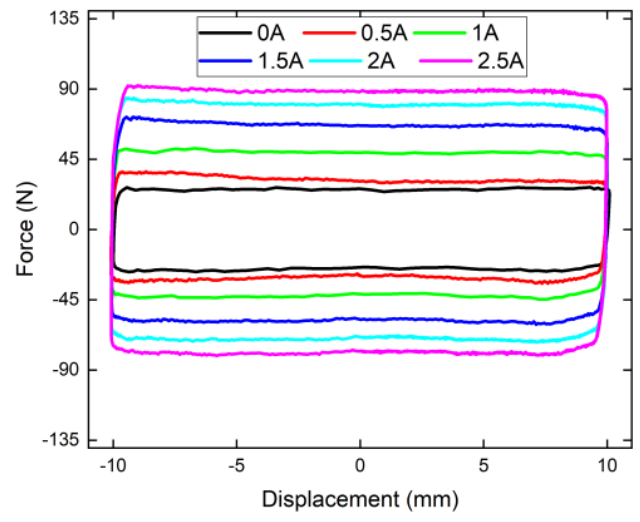

(a)

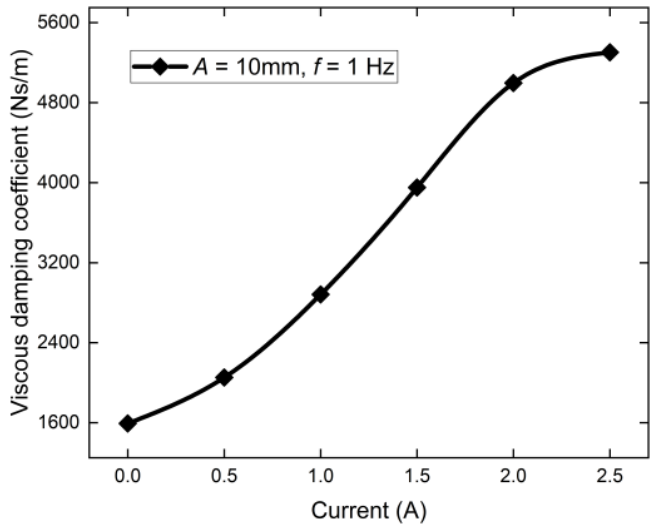

(b) 


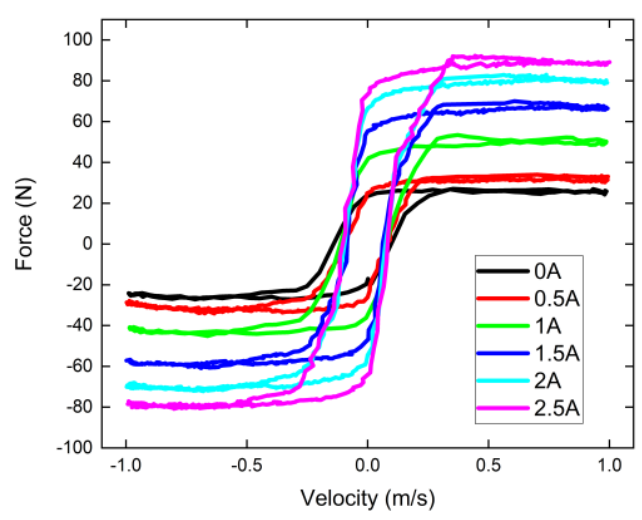

(c)

Figure 5. Variable damping behavior under different damper current $(A=10 \mathrm{~mm}, f=1 \mathrm{~Hz})$

(a) Force-displacement loops (b) Equivalent damping coefficient (c) Force-velocity loops

\subsubsection{Amplitude dependency}

The amplitude dependence of the MR damper under three amplitudes, $A=7 \mathrm{~mm}, 10 \mathrm{~mm}$ and $13 \mathrm{~mm}$, with the current of $I=1 \mathrm{~A}$ and frequency of $f=0.5 \mathrm{~Hz}$, is presented in Figure 6(a). The peak force is almost the same for all the amplitude cases. As shown in Figure 6(b), the equivalent damping coefficient shows a decreasing trend with the increase of the displacement, because the equivalent damping coefficient is inversely proportional to the square of amplitude.

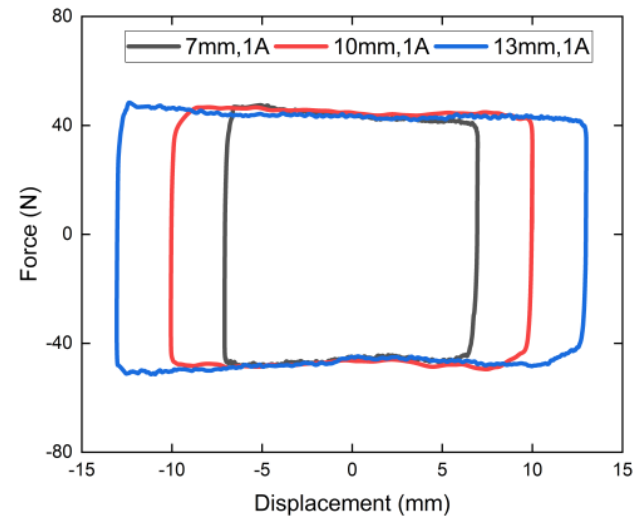

(a)

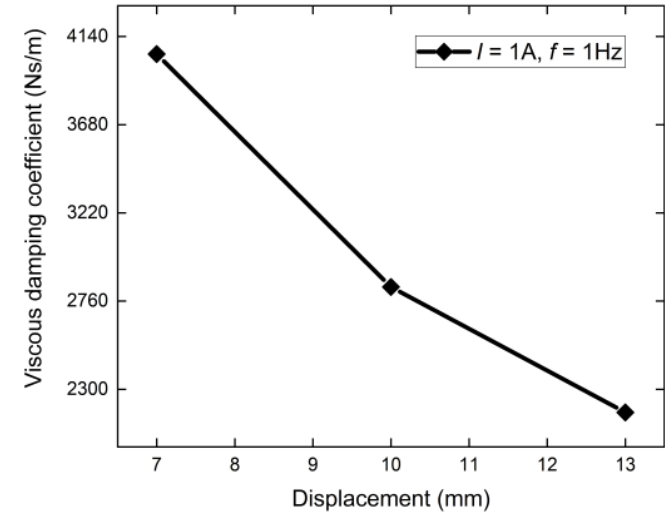

(b)

Figure 6. Damper performance under different amplitudes $(I=1 \mathrm{~A}, f=1 \mathrm{~Hz})$

(a) Force-displacement loops (b) Equivalent damping coefficient

\subsubsection{Frequency dependent}

As shown in Figure 7, the frequency dependent of the MR damper under various loading frequencies: $\mathrm{f}=1,3$ and $5 \mathrm{~Hz}$, with the excitation amplitude $A=10 \mathrm{~mm}$ and the current $\mathrm{I}=2.5 \mathrm{~A}$, is presented. The peak damping force is almost the same under all three frequencies. The equivalent damping coefficient, however, decreases with the increasing frequency $f$ because the equivalent damping coefficient is inversely proportional to the excitation frequency. 


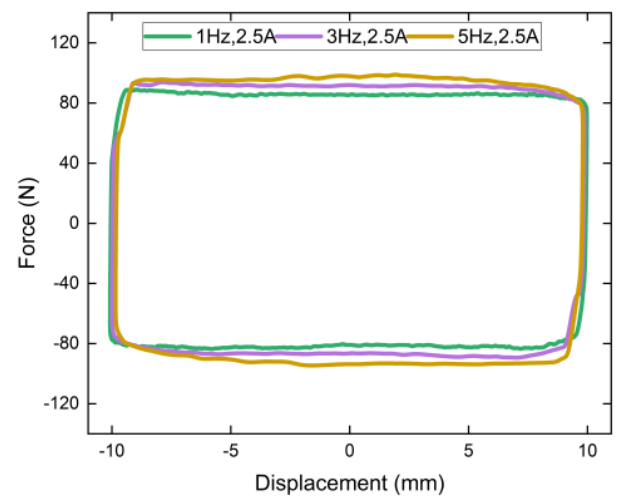

(a)

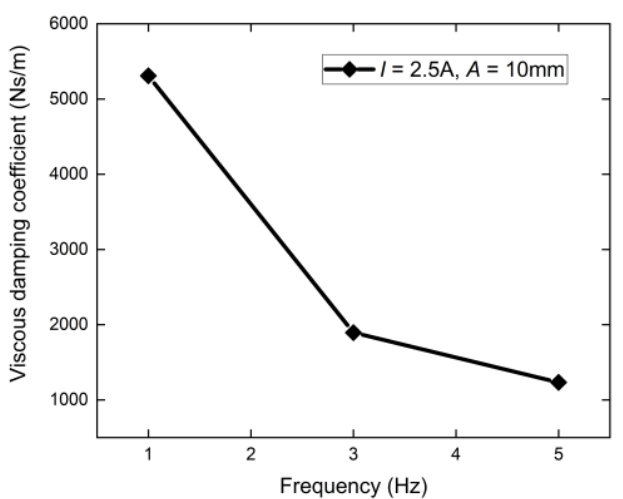

(b)

Figure 7. Frequency dependent $(I=2.5 \mathrm{~A}, A=10 \mathrm{~mm})$

(a) Force-displacement relationship (b) Equivalent damping coefficient

\section{The effectiveness valuation of the MR damper on the vibration attenuation}

\section{of TBM}

\subsection{Experimental setup for the evaluation system}

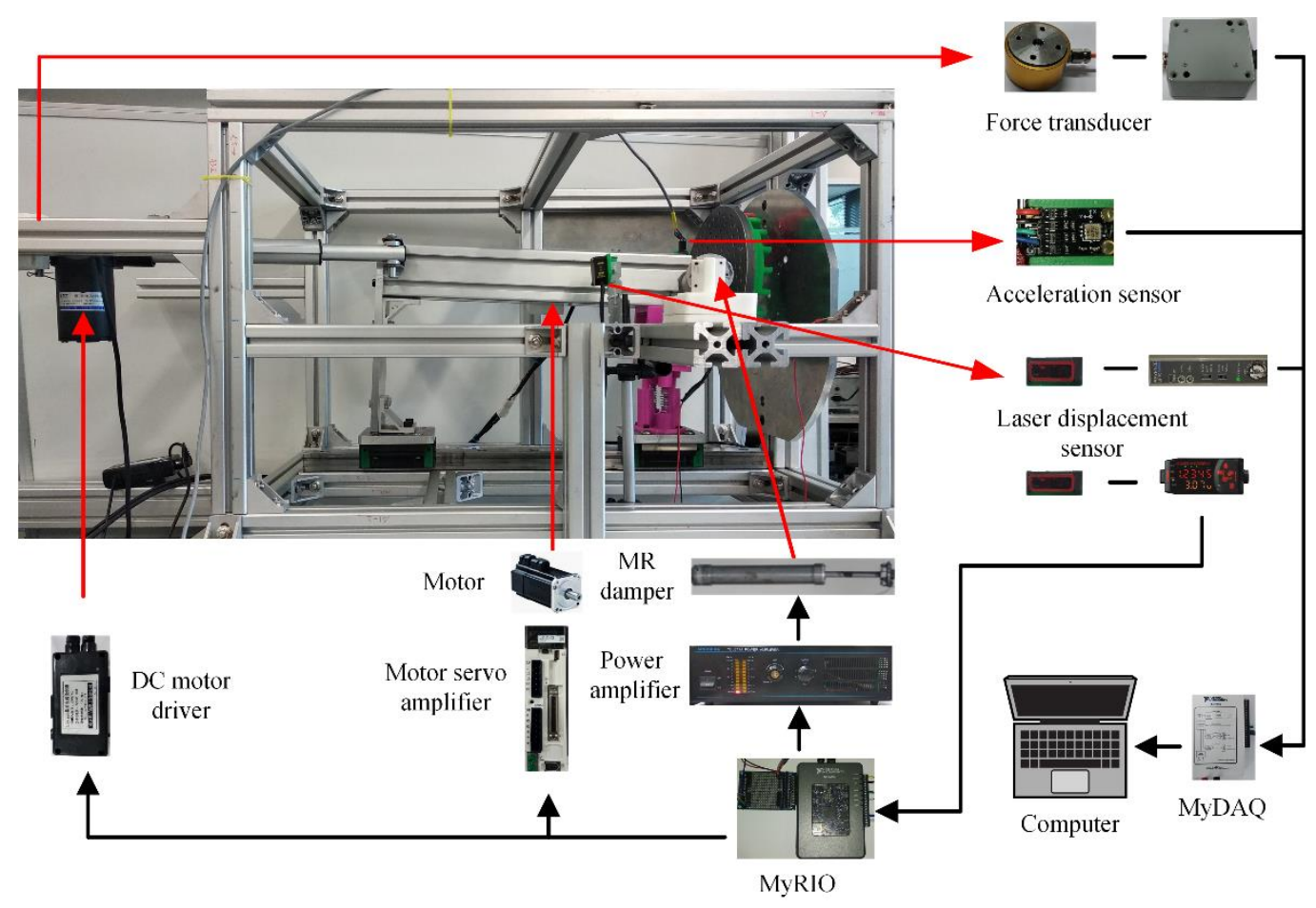

Figure 8. Hardware of the control loop

The test platform is shown in Figure 8. The primary parameters of the TBM test platform are $m=32.2 \mathrm{Kg}, k=10121 \mathrm{Nm}^{-1}, c=510 \mathrm{Nsm}^{-1}$. Where, $m$ is the structure mass; $k$ is the stiffness in horizontal direction; $\mathrm{c}$ is the damping coefficient, composing of structure damping and MR damping in zero input current. During the test, the cutterhead is excited by colliding with plastic 
bump (simulate hard rock) or cutting soft materials (simulate soft rock). In the control loop, a laser displacement sensor (Model: ZX-LD 40, Omron Corp.) acquires vibration displacement and converted to analog voltage signal by an amplifier (Model: ZX-L-N11-N, Omron Corp). The displacement signal is sent to a real-time control board (Model: myRIO-1900, NI Corp.) to calculate the required control signal for the MR damper. The control signal will be driven by a power amplifier and then sent to control the MR damper.

Another control loop is adopted to control the feed movement and rotational motion of the testing platform. A DC motor amplifier drives the linear actuator to push the cutterhead, and a servo motor amplifier controls the AC servo motor to spin the cutterhead. Both amplifiers are connected to the real-time control board.

Regarding the system monitoring, an acceleration sensor (ADXL202, Analog Devices Corp.) and a laser displacement (Model: LB-11, Keyence Corp.) are employed to measure acceleration and displacement of girder respectively. A force transducer (Model: DYZ-101, Dayang Crop.) is installed at the end of the linear actuator to monitor the propulsion force. These signals are collected by a data acquisition board (Model: myDAQ, NI Corp.) and then recorded in a computer.

\subsection{Control algorithm design}

The controller is designed with the capability of adapting to different geological conditions in this section. As shown in Figure 9, a displacement sensor is used to detect what kind of geological conditions the TBM is working on. If the TBM is cutting soft rock, the vibration amplitude of the TBM will be lower than the threshold and the required damping for vibration reduction is small in this scenario. Consequently, the MR damper will be operating at off-state to reduce the required propulsion force. When the system is cutting hard rock, the vibration of the TBM be fierce and the vibration amplitude will be higher than the threshold. In this case the sky-hook controller will be turned on to control the MR damper. In this test, the threshold is set to be $0.3 \mathrm{~mm}$. The control law is given by the following equation [25]:

$$
\begin{cases}c_{\text {in }}(\mathrm{t})=c_{\max }, & \text { if } \dot{z} z \geq 0 \\ c_{\text {in }}(\mathrm{t})=c_{\min }, & \text { if } \dot{z} z<0\end{cases}
$$

where $c_{\text {in }}(\mathrm{t}), c_{\max }$, and $c_{\min }$ are the real-time damping of the MR damper, the maximum and the minimum damping, respectively; $\dot{z}$ and $z$ are horizontal velocity and displacement of the girder, respectively. In this experiment, the specific current is set to be $2.5 \mathrm{~A}$ for the maximum damping and $0 \mathrm{~A}$ for the minimum damping. This strategy indicates that if the relative displacement of the girder with respect to the tunnel is in the same direction as that of the velocity, then a maximum damping force should be applied to block movement away from the center position. On the other hand, if the directions of displacement and velocity are in the opposite directions, the damping force should be at a minimum to get the girder back to the center as quickly as possible. The base principle is shown in Figure 9. Another point to note is that the negative stiffness of MR damper has little influence on the system, this control process ignores it. 


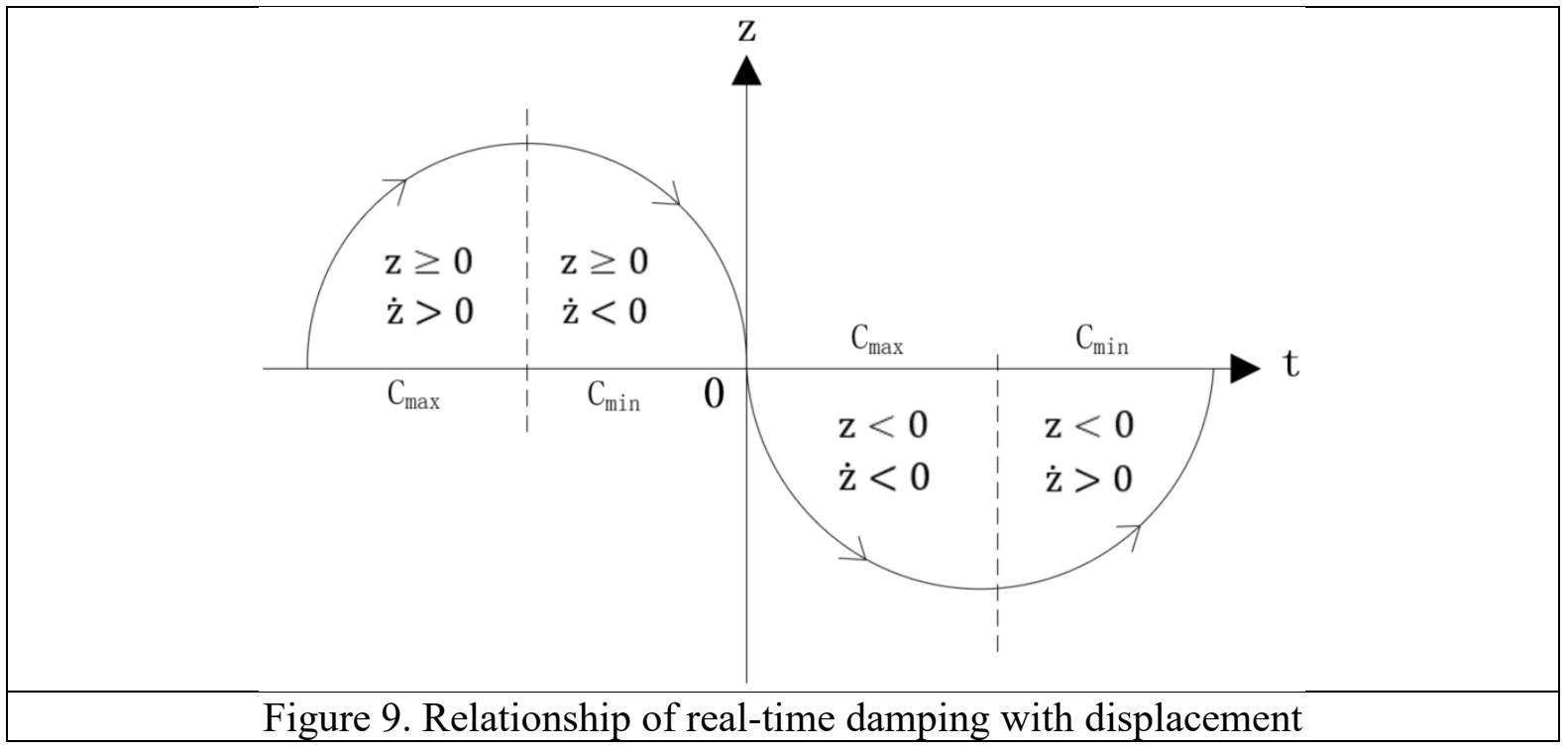

The control loop of sky-hook controller is detailed as follows: the laser sensor collects the vibration displacement of the girder; the displacement values are differentiated into the velocity of the girder. The controller controls the current to the MR damper according to the multiplication of the displacement and velocity of girder.

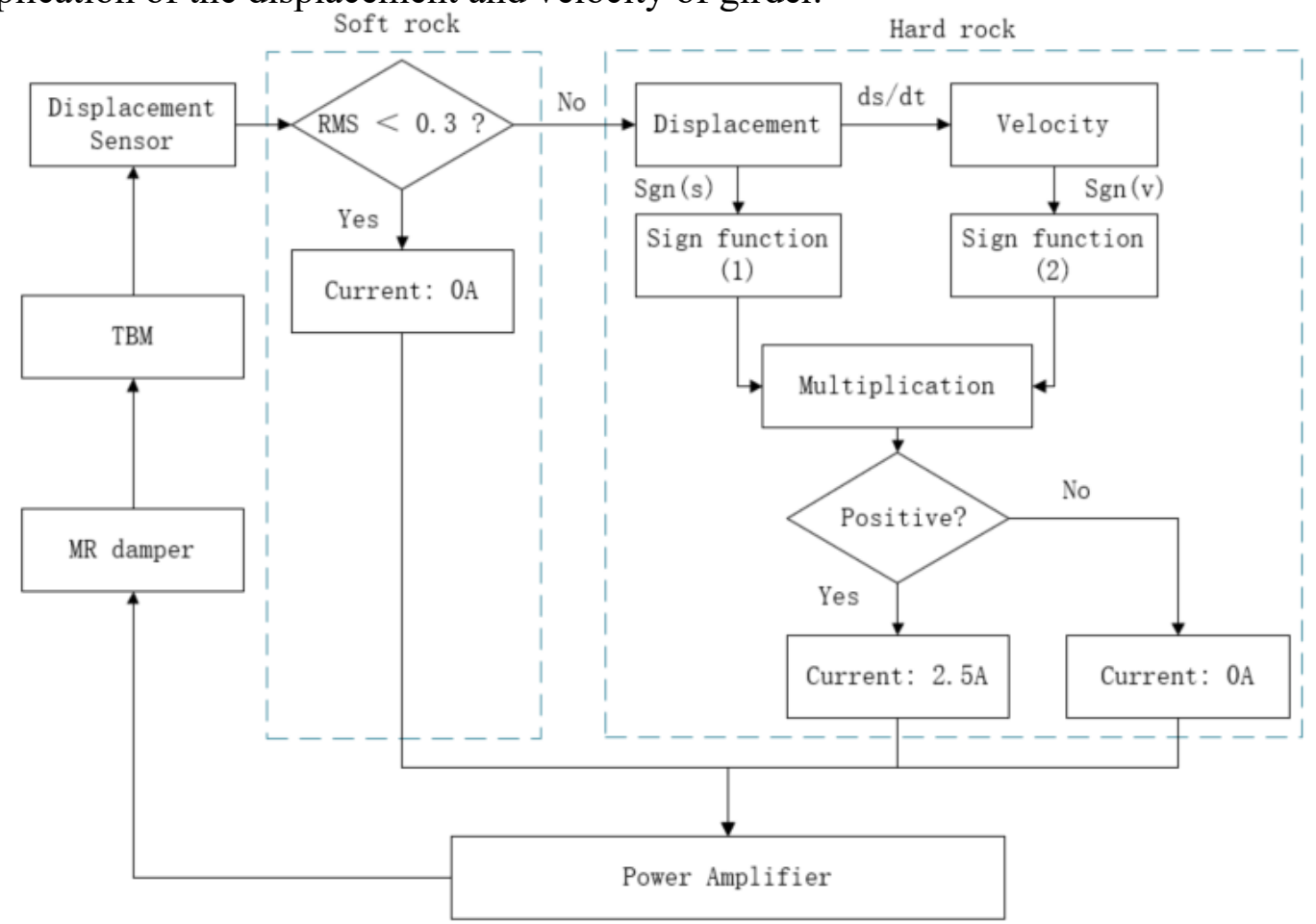

Figure 10. Schematic of the control flow

The control signal waveform is shown in Figure 11. Noted that the vibration displacement is acquired during hard rock excavation. 


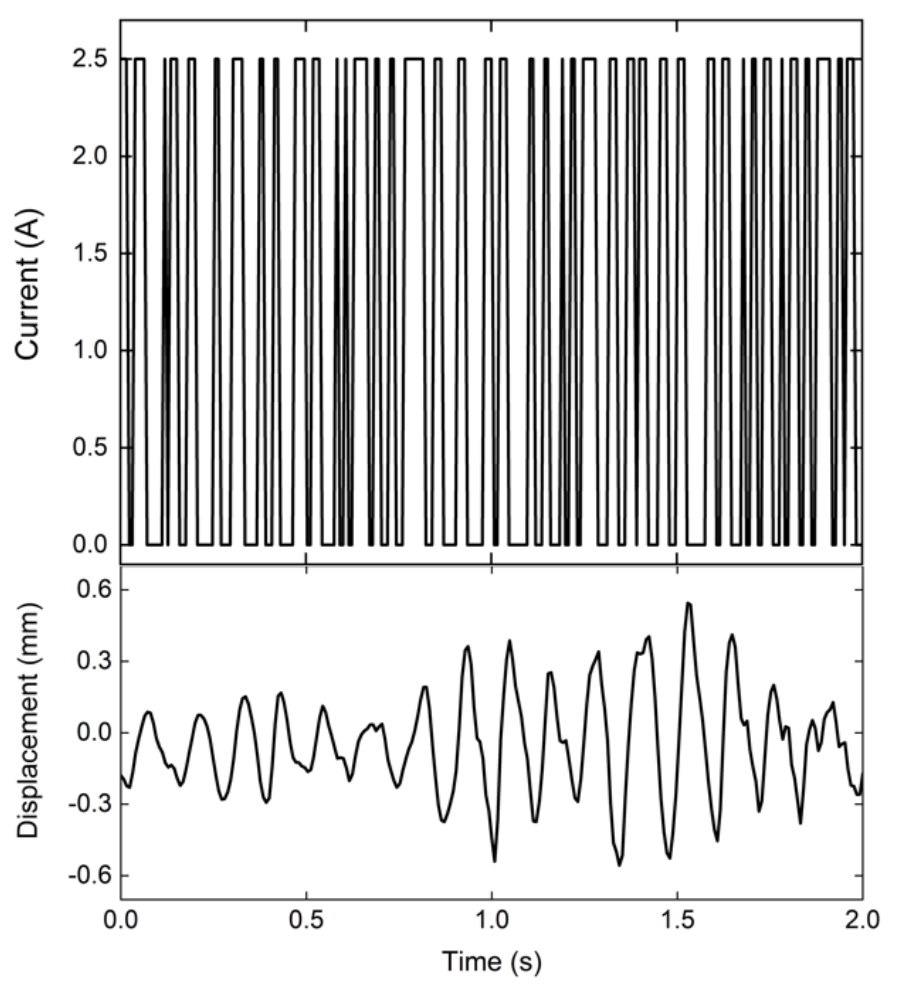

Figure 11. Control signal waveform

\section{Testing results and analysis}

The performance of the TBM installed with an MR damper is evaluated under both hard rock and soft rock excavation conditions. 3D printed plastic plates is used to simulate hard rock while a foam is used to imitate the soft rock during the evaluation. The detailed evaluation results are illustrated as follows.

\subsection{Evaluation under hard rock geological condition}

During this test, both the displacement and acceleration of the girder are collected and evaluated. The displacements of the girder under different cutting depth are presented in Figure 12. Three different working modes of the MR damper, i.e., controller off, controller on and passive on, are evaluated. From the picture, it can be seen that the vibration amplitude significantly decreased with the controller being turned on at 10s. Specifically, the vibration amplitude reduced by $46.92 \%$ from $0.569 \mathrm{~mm}$ to $0.302 \mathrm{~mm}$ under $2 \mathrm{~mm}$ excavation depth. What more, the MR damper performed better when the excavation depth changed to be $4 \mathrm{~mm}$. In particular, the amplitude reduced by $52.14 \%$ from $0.817 \mathrm{~mm}$ to $0.391 \mathrm{~mm}$, as shown in Figure 12(b). As a comparison, the TBM installed with a passive-on state MR damper (the current to be set as constant $2.5 \mathrm{~A}$ ) is evaluated as well and the testing results are presented in Figure 12. The effect of the passive-on state MR damper is similar to the controlled case. However, energy consumption of using sky-hook controller is more less than the consumption with turning on the damper continually. The detailed results are listed in Table 2. 


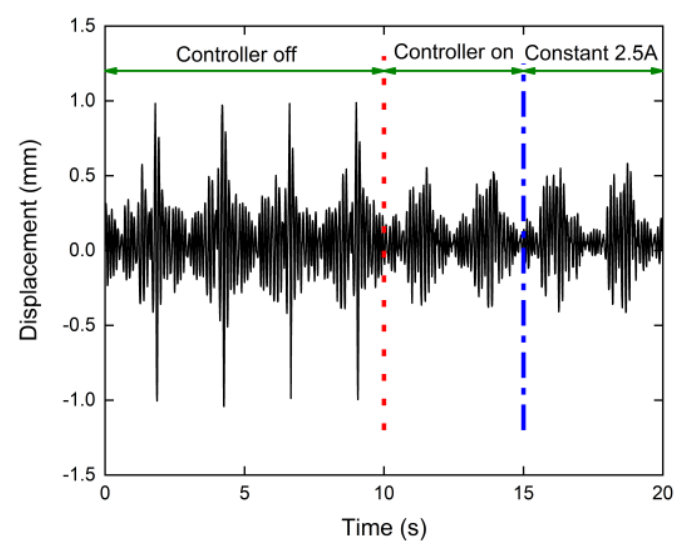

(a)

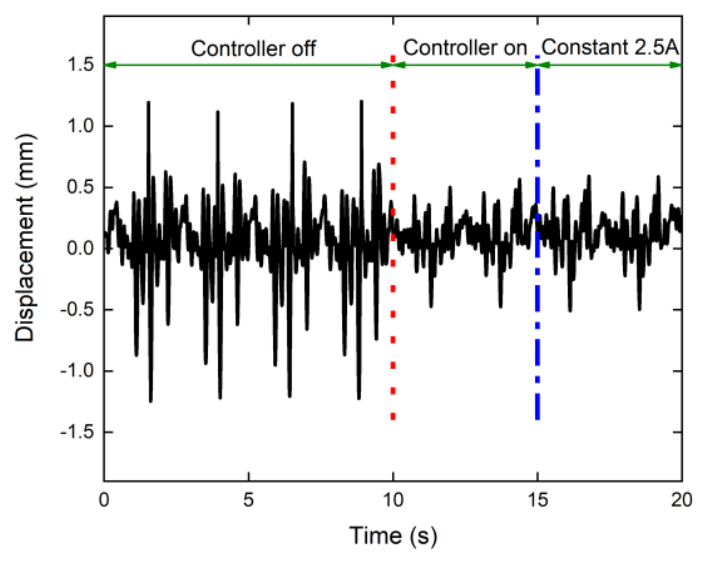

(b)

Figure 12. Displacement response of excavating hard rock (a) $2 \mathrm{~mm}$ depth (b) $4 \mathrm{~mm}$ depth.

Table 3. Displacement data of excavating hard rock

\begin{tabular}{cc|cc|cc}
\hline $\begin{array}{c}\text { Excavation } \\
\text { Depth }(\mathrm{mm})\end{array}$ & Controller off & \multicolumn{2}{|c|}{ Controller on } & \multicolumn{2}{c}{ constant 2.5A } \\
& & RMS value & $\begin{array}{c}\text { Percentage of } \\
\text { controller off }\end{array}$ & RMS value & $\begin{array}{c}\text { Percentage of } \\
\text { controller off }\end{array}$ \\
\hline 2 & 0.569 & 0.302 & $46.92 \%$ & 0.311 & $45.34 \%$ \\
4 & 0.817 & 0.391 & $52.14 \%$ & 0.401 & $50.92 \%$ \\
\hline
\end{tabular}

The acceleration has a direct impact on the comfort of the operator and the mechanical reliability of the TBM. The accelerations of TBM are show in Figure $\mathbf{1 3}$ and Table 3. The acceleration amplitude drops by $50.08 \%$ from $0.581 \mathrm{~g}$ to $0.290 \mathrm{~g}$ when the excavation depth is $2 \mathrm{~mm}$, as shown in Figure 13(a). Similar with the above results, using MR damper can reduce the vibration acceleration by $53.31 \%$ when the excavation depth is $4 \mathrm{~mm}$, as shown in Figure 13(b). When the damper is energized with a constant $2.5 \mathrm{~A}$ current, it can also achieve a similar performance with the controlled case, but the MR damper with constant current consumes more energy compared with skyhook controlled case.

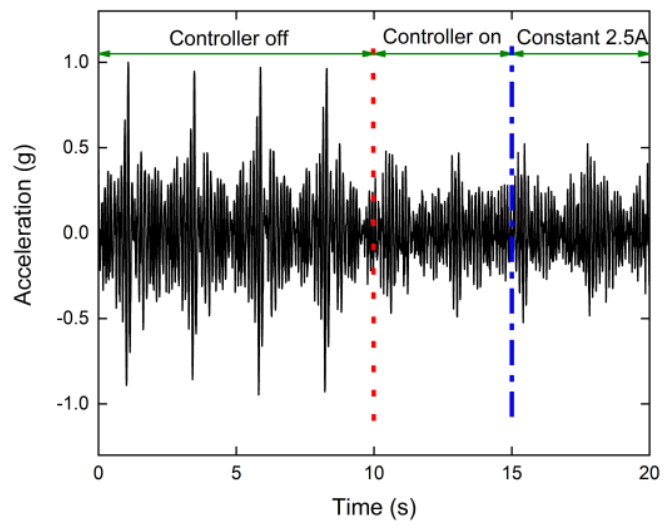

(a)

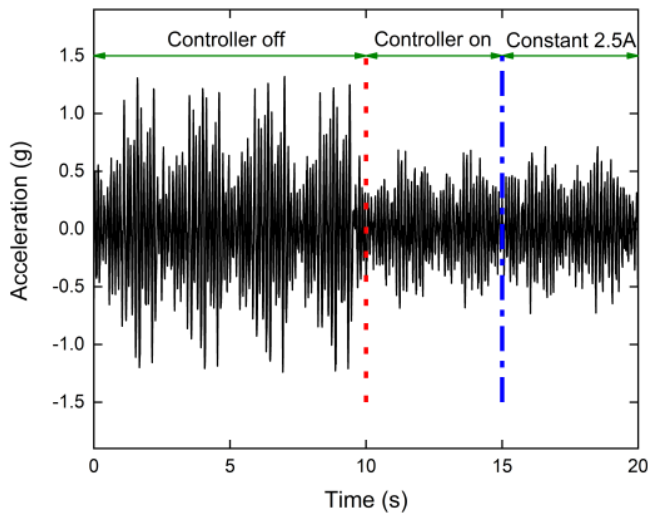

(b)

Figure 13. Acceleration response f excavating hard rock

(a) $2 \mathrm{~mm}$ depth (b) $4 \mathrm{~mm}$ depth.

Table 3. Acceleration data of excavating hard rock

\begin{tabular}{lccccc} 
Excavation & & \multicolumn{2}{c}{ Controller on } & \multicolumn{2}{c}{ constant 2.5A } \\
Depth $(\mathrm{mm})$ & Controller off & RMS value & Percentage of & RMS value & $\begin{array}{c}\text { Percentage of } \\
\text { controller off }\end{array}$ \\
\hline
\end{tabular}




\begin{tabular}{llllll}
\hline 2 & 0.581 & 0.290 & $50.08 \%$ & 0.292 & $49.74 \%$ \\
4 & 0.883 & 0.413 & $53.31 \%$ & 0.426 & $51.75 \%$ \\
\hline
\end{tabular}

The propulsive force of the TBM under different control cases during excavating hard rock are shown in Figure 14 and Table 4. From Figure 14 (a) it can be seen that the propulsive force only slightly increases during the excavation with $2 \mathrm{~mm}$ depth when the controller is turned on. In particular, the force amplitude increased by $14.92 \%$ from 93.95 to $104.23 \mathrm{~N}$ under. For 4 $\mathrm{mm}$ excavation depth, the increase of propulsive force is similar with $2 \mathrm{~mm}$ excavation depth, i.e., increases by $17.7 \%$. The case with MR damper energized with a 2.5 A current performs similar with the controller-on case.

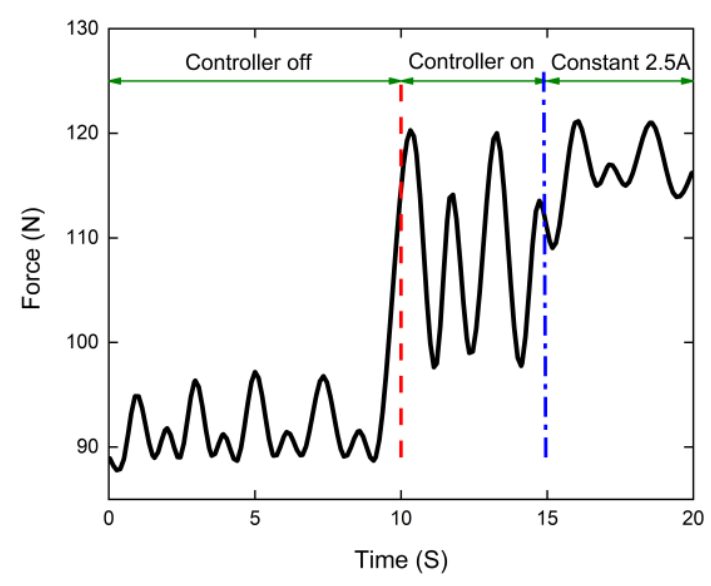

(a)

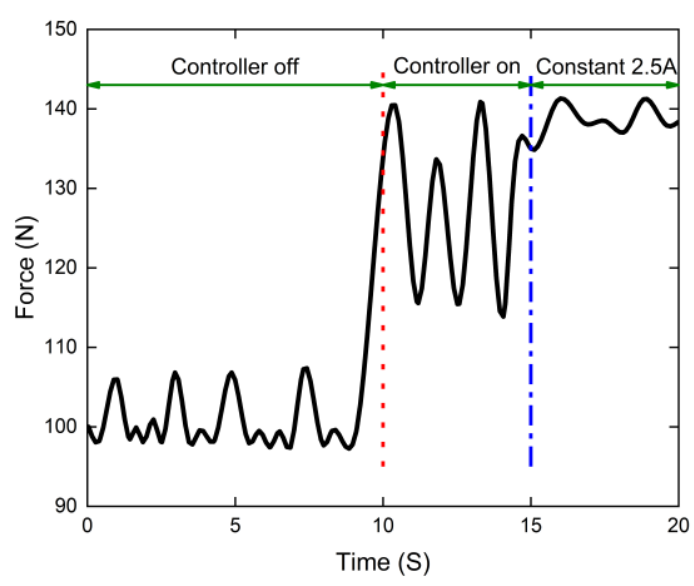

(b)

Figure 14. Force response of excavating hard rock

(a) $2 \mathrm{~mm}$ depth (b) $4 \mathrm{~mm}$ depth.

Table 4. Force data of excavating hard rock

\begin{tabular}{cccccc}
\hline $\begin{array}{c}\text { Excavation } \\
\text { Depth }(\mathrm{mm})\end{array}$ & Controller off & \multicolumn{2}{c}{ Controller on } & \multicolumn{2}{c}{ constant 2.5A } \\
& RMS value & $\begin{array}{c}\text { Percentage of } \\
\text { controller off }\end{array}$ & $\begin{array}{c}\text { RMS value } \\
(\mathrm{N})\end{array}$ & $\begin{array}{c}\text { Percentage of } \\
\text { controller off }\end{array}$ \\
\hline 2 & 93.95 & 104.23 & $114.92 \%$ & 118.30 & $125.92 \%$ \\
4 & 104.57 & 123.07 & $117.69 \%$ & 135.50 & $129.58 \%$ \\
\hline
\end{tabular}

The frequency response under the states of turning the controller on or off is shown in Figure 15. From Figure 15 (a) it can be seen that the acceleration amplitude has a significant reduction in low-band frequency after turning on controller. However, above $13.7 \mathrm{~Hz}$ frequency the damping effect is not significant. During the excavation with $4 \mathrm{~mm}$, the test results are similar to the results of excavating $2 \mathrm{~mm}$ shown in Figure 15(b). 


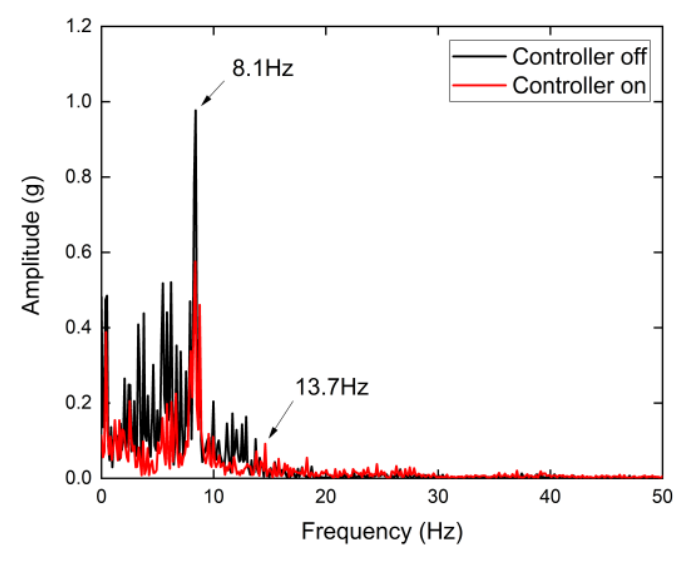

(a)

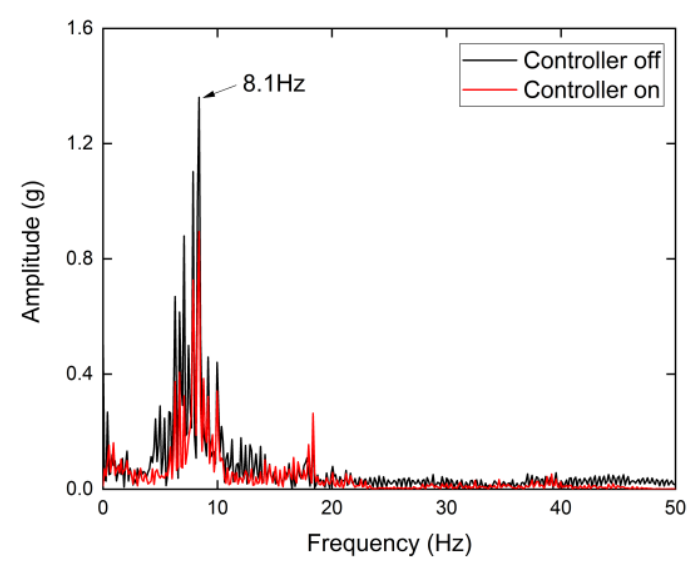

(b)

Figure 15. Frequency response of excavating hard rock

(a) $2 \mathrm{~mm}$ depth (b) $4 \mathrm{~mm}$ depth.

In summary, the controlled MR damper can reduce vibration displacement by $51.62 \%$ and reduce acceleration by $52.18 \%$ during hard-rock excavation and can perform better if the excavation depth increases. In addition, the controlled case and the passive-on case perform similar and much better than control-off case during hard-rock excavation.

\subsection{Evaluation under soft rock geological condition}

As is shown in Figure 16(a), when the soft rock is being excavated, the displacement amplitude is only $0.23 \mathrm{~mm}$, and the vibration amplitude of the girder is lower than the threshold; then the controlled set the current to be $0 \mathrm{~A}$. This is the reason why the controller-off case and controlleron case perform similar. As a comparison, the performance of the passive-on case is evaluated as well. From the testing results it can be seen that the vibration amplitude is slightly reduced to $0.21 \mathrm{~mm}$ with the current being set to $2.5 \mathrm{~A}$, this is because the vibration of TBM is small during soft-rock excavation. The acceleration during soft rock excavation are also presented in Figure 16(b). When the soft rock is being excavated, the acceleration under controller-off and controller-on states is only $0.16 \mathrm{~g}$. The acceleration is reduced to $0.15 \mathrm{~g}$ when the damper is powered with a constant $2.5 \mathrm{~A}$ current.

The propulsion force is another significant evaluation factor for the TBM. The propulsion force under different control cases is collected and presented in Figure 16. From this figure it can be seen that the propulsion force of the controller-off and controller-on cases are similar and much smaller than the passive-on case; this means the passive-on case will consume too much energy during the excavation. Considering the vibration reduction performance of passive-on case is only slightly better than the other two cases, it can be concluded that the overall performances of the controller-on and controller-off cases are much better than the passive-on case during cutting soft rocks. 


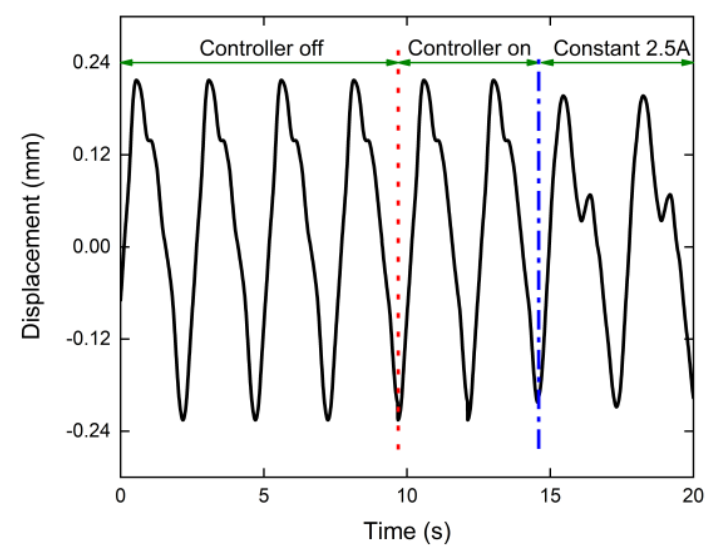

(a)

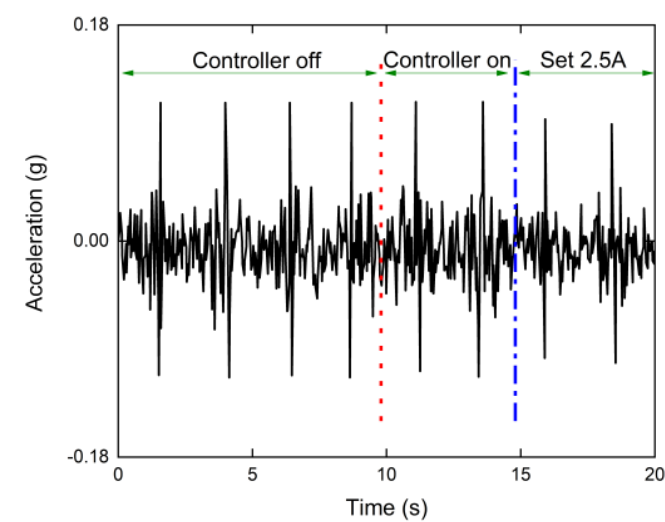

(b)

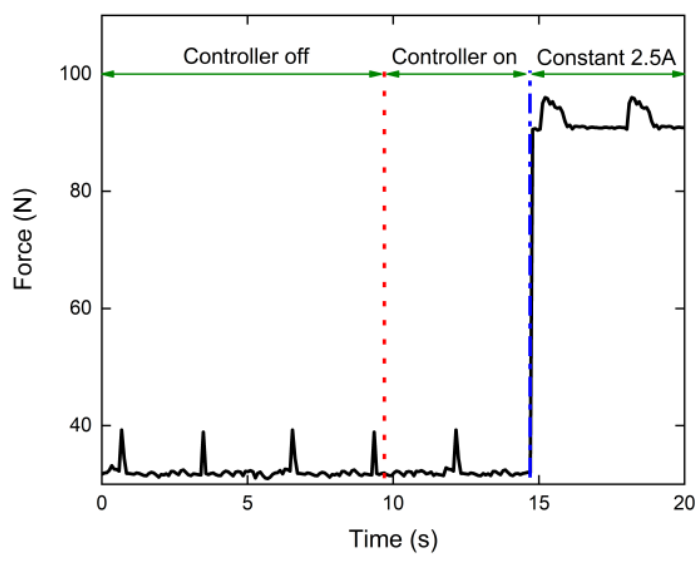

(c)

Figure 16. Responses of excavating soft rock.

(a) Displacement (b) Acceleration (c)Force

Summarily, the vibration reduction performance and propulsive force under different tunneling conditions and control cases are compared in Table 5. Considering the vibration reduction capability and the propulsive force increase, the following conclusion can be drawn. Firstly, the overall performance of the controller-on case and the controller-off cases is much better than the passive-on case during soft rock excavation because the passive-on case only performs slightly better than the other two cases, but its propulsive force significantly increased. For the hard rock excavation condition, the overall performance of the control-on case and passive-on case is much better than controller-off case because the vibration suppression of the controlleron and passive-on cases is much better than the controller-off case, in the meanwhile their propulsion force only increased slightly. When we consider both of the two geological conditions, we can find out that the controller-on MR damper performs good under both the two excavation conditions while the other two cases can only adapt to one geological condition.

Table 5. Comparison of vibration reduction effects during different rocks

\begin{tabular}{c|c|ccc}
\hline Geological condition & Items & 0A input & Controller on & $2.5 \mathrm{~A}$ input \\
\hline \multirow{2}{*}{ Soft rock } & Vibration displacement $(\mathrm{mm})$ & 0.23 & 0.23 & 0.21 \\
& Propulsive force $(\mathrm{N})$ & 38.89 & 38.90 & 96.11 \\
\hline \multirow{2}{*}{ Hard rock } & Vibration displacement $(\mathrm{mm})$ & 0.883 & 0.413 & 0.426 \\
& Propulsive force $(\mathrm{N})$ & 104.57 & 123.07 & 135.50 \\
\hline
\end{tabular}




\section{Conclusion}

This paper proposed an adaptive MR damper to work as a novel solution to reduce horizontal vibration of TBM. Through MTS experiment, the MR damper's minimum and maximum damping force are $25.19 \mathrm{~N}$ and $95.12 \mathrm{~N}$ respectively, and the equivalent damping coefficients are $97.4 \mathrm{Nsm}^{-1}$ and $2238.8 \mathrm{Nsm}^{-1}$ respectively. The adaptability of the MR damper on vibration reduction of TBM under different geological conditions is successfully experimentally verified. The controlled MR damper can reduce the horizontal vibration of TBM by up to $53.31 \%$ with only slightly propulsive force increase under hard rock excavation. During the soft-rock excavation, the MR damper can maintain the propulsive force of TBM to be low and performs similar with large damping damper on vibration reduction. In summary, the controlled MR damper can control the vibration of a TBM without inducing significant propulsion force increase during different excavation conditions.

\section{Acknowledgments}

This research is supported by China Scholarship Council. This financial support is appreciated.

\section{References}

[1] Liu, Q., Huang, X., Gong, Q., Du, L., Pan, Y., \& Liu, J. (2016). Application and development of hard rock TBM and its prospect in China. Tunnelling and Underground Space Technology, 57, 33-46.

[2] Zhao, J., Gong, Q. M., \& Eisensten, Z. (2007). Tunnelling through a frequently changing and mixed ground: a case history in Singapore. Tunnelling and Underground Space Technology, 22(4), 388-400.

[3] Ling, J., Sun, W., Huo, J., \& Guo, L. (2015). Study of TBM cutterhead fatigue crack propagation life based on multi-degree of freedom coupling system dynamics. Computers \& Industrial Engineering, 83, 1-14.

[4] Huo, J., Zhu, D., Hou, N., Sun, W., \& Dong, J. (2017). Application of a small-timescale fatigue, crack-growth model to the plane stress/strain transition in predicting the lifetime of a tunnel-boring-machine cutter head. Engineering Failure Analysis, 71, 11-30.

[5] Bilgin, N., Feridunoglu, C., Tumac, D., Cinar, M., Palakci, Y., Gunduz, O., \& Ozyol, L. (2005, May). The performance of a full face tunnel boring machine (TBM) in Tarabya (Istanbul). In Proceedings, 31st ITA-AITES World Tunnel Congress (pp. 821-826).

[6] Zou, X., Mi, Y., Zheng, H., \& Tao, J. (2016, August). Influence of vibration on the performance of tunnel boring machines. In 2016 12th IEEE/ASME International Conference on Mechatronic and Embedded Systems and Applications (MESA) (pp. 1-6). IEEE.

[7] Huo, J., Wu, H., Li, G., Sun, W., \& Chen, J. (2015). The coupling dynamic analysis and field test of TBM main system under multipoint impact excitation. Shock and Vibration, 2015. [8] Xie, J., Ke, T., \& Yang, D. (2010, November). The effect of TBM hydraulic piping system parameters on FSI vibration. In International Conference on Intelligent Robotics and Applications (pp. 363-371). Springer, Berlin, Heidelberg.

[9] Yang, B., zhang, A., Bai, Y., Zhang, K., \& Li, H. (2018). Development and simulation of a magnetorheological damper for segment erector vibration control. Transactions of the Canadian Society for Mechanical Engineering, (ja)

[10] Gustafsson, N. (2011). Wire cutting as a complement to drill and blast in vibration sensitive environments.

[11] Lee, J. H., Ahn, S. K., Lee, K. C., Bang, C. S., Cho, J. H., \& Sagong, M. (2017). Wire saw 
cutting model development and performance investigation for vibration reduced tunnel excavation. Tunnelling and Underground Space Technology, 63, 144-153.

[12] Wu, J., Pei, L., Xuan, S., Yan, Q., \& Gong, X. (2016). Particle size dependent rheological property in magnetic fluid. Journal of Magnetism and Magnetic Materials, 408, 18-25.

[13] Hu, M., Wang, J., Shen, T., Liu, B., \& Wang, J. H. (2015, November). The Study on Shear Thinning Behavior of the Magnetorheological Fluid Under High Velocity Flow. In ASME 2015 International Mechanical Engineering Congress and Exposition (pp. V07BT09A047V07BT09A047). American Society of Mechanical Engineers.

[14] Deng, H., Han, G., Zhang, J., Wang, M., Ma, M., Zhong, X., \& Yu, L. (2018). Development of a non-piston MR suspension rod for variable mass systems. Smart Materials and Structures, 27(6), 065014.

[15] Bai, X. X., Shen, S., Cai, F. L., Deng, X. C., \& Xu, S. X. (2018, March). Mechanical responses of a magnetorheological damper. In Active and Passive Smart Structures and Integrated Systems XII (Vol. 10595, p. 1059507). International Society for Optics and Photonics.

[16] Cesmeci, S., Gordaninejad, F., Ryan, K. L., \& Eltahawy, W. (2018). A liquid springmagnetorheological damper system under combined axial and shear loading for threedimensional seismic isolation of structures. Journal of Intelligent Material Systems and Structures, 29(18), 3517-3532.

[17] Yu, J., Dong, X., \& Zhang, Z. (2017). A novel model of magnetorheological damper with hysteresis division. Smart Materials and Structures, 26(10), 105042.

[18] Xing, Z., Yu, M., Sun, S., Fu, J., \& Li, W. (2015). A hybrid magnetorheological elastomerfluid (MRE-F) isolation mount: development and experimental validation. Smart materials and structures, 25(1), 015026.

[19] Choi, S. B., Li, W., Yu, M., Du, H., Fu, J., \& Do, P. X. (2016). State of the art of control schemes for smart systems featuring magneto-rheological materials. Smart Materials and Structures, 25(4), 043001.

[20] Choi, Y. T., Robinson, R., Hu, W., Wereley, N. M., Birchette, T. S., Bolukbasi, A. O., \& Woodhouse, J. (2016). Analysis and control of a magnetorheological landing gear system for a helicopter. Journal of the American Helicopter Society, 61(3), 1-8.

[21] Lam, A. H. F., \& Liao, W. H. (2003). Semi-active control of automotive suspension systems with magneto-rheological dampers. International Journal of Vehicle Design, 33(1-3), 50-75.

[22] Lai, C. Y., \& Liao, W. H. (2002). Vibration control of a suspension system via a magnetorheological fluid damper. Modal Analysis, 8(4), 527-547.

[23] Li, Y., Li, J., Li, W., \& Samali, B. (2013). Development and characterization of a magnetorheological elastomer based adaptive seismic isolator. Smart Materials and Structures, 22(3), 035005.

[24] Weber, F., \& Maślanka, M. (2013). Precise stiffness and damping emulation with MR dampers and its application to semi-active tuned mass dampers of Wolgograd Bridge. Smart Materials and Structures, 23(1), 015019.

[25] Liao, G. J., Gong, X. L., Xuan, S. H., Kang, C. J., \& Zong, L. H. (2012). Development of a realtime tunable stiffness and damping vibration isolator based on magnetorheological elastomer. Journal of Intelligent Material Systems and Structures, 23(1), 25-33. 